\title{
Visual functions and disability in Iranian adults: a population-based study
}

\author{
Hassan Hashemi ${ }^{1}$, Fatemeh Mehravar ${ }^{2}$, Soheila Asgari ${ }^{1}$, Mohammad Hassan Emamian ${ }^{3 *}$ and Akbar Fotouhi $^{2}$
}

\begin{abstract}
Background: Vision-related quality of life is related to severity of visual impairments and show the impact of eye diseases on daily activities. This study aims to assess visual functions and disability and its association with age, gender, education, marital status, and economic status in adults aged 45-69years.

Methods: Data in this population-based study were from the second phase of the Shahroud eye cohort study and collected by using a Short-Form Visual Functioning Scale. The scores of visual function and disability were calculated based on Rasch-transformed scores of the National Eye Institute visual functioning questionnaire, where a more negative score indicates a better situation. Multiple linear regression was used to investigate the factors associated with visual functions.

Results: Among 4737 participants the visual function data for 4715 people were analyzed. The visual function of 75.3, 17.1 and $7.5 \%$ of participants were "ideal and good", "moderate", and "bad and very bad", respectively, while $0.06 \%$ were unable for vision. The running mean of the visual function was calculated to be $-3.95 \pm 0.02$. The visual performance was worse in females than the males $(\beta=0.14, p=0.005)$. Visual function improved with increasing levels of education $(\beta=-1.06, p<0.001)$. It was worse in low-economic $(\beta=0.016, p=0.005)$ and moderate-economic $(\beta=0.28$, $\mathrm{p}<0.001)$ participants than high-economic ones.
\end{abstract}

Conclusion: The visual function of Iranian adults aged 45-69years was moderate. The male gender, higher education and the higher economic status had a better visual function.

Keywords: Visual function, Short-form visual functioning scale, NEI-VFQ, Population-based study

\section{Introduction}

According to the WHO's latest report, global estimates on visual impairment show that 2.2 billion people have a vision impairment and majority of them are over the age of 50 years [1]. According to the Global Vision Database Maps, about 217 million people have a moderate and severe visual impairment, of which $0.4 \%$ are blind; the global prevalence of distant visual impairment is also estimated to be 3.4\%. According to the Lancet Global health 2021, more than 295 million people have a moderate

*Correspondence: emamian@shmu.ac.ir

${ }^{3}$ Ophthalmic Epidemiology Research Center, Shahroud University of Medical Sciences, Shahroud, Iran

Full list of author information is available at the end of the article and severe visual impairment, of which $0.55 \%$ are blind. Despite of a $27 \%$ reduction in proportion of blindness from 1990 up to now, the total number of people with blindness and moderate and severe vision impairment has increased significantly (by 51 and 92\%, respectively) [2]. Chronic ocular diseases can significantly affect the quality of life of these patients, therefore, evaluating the visual quality can recognize the perception and feeling of visual performance and quality of life after ocular disease.

Vision-related quality of life (VRQoL) is an outstanding and measurable health outcome in patients with visual impairment [3], that indicates the impact of the chronic eye disease on daily activities [4]. The VRQoL can be evaluated by measuring the degree of disability experienced by a person in vision-related daily activities [5]. original author(s) and the source, provide a link to the Creative Commons licence, and indicate if changes were made. The images or other third party material in this article are included in the article's Creative Commons licence, unless indicated otherwise in a credit line to the material. If material is not included in the article's Creative Commons licence and your intended use is not permitted by statutory regulation or exceeds the permitted use, you will need to obtain permission directly from the copyright holder. To view a copy of this licence, visit http://creativecommons.org/licenses/by/4.0/. The Creative Commons Public Domain Dedication waiver (http://creativeco mmons.org/publicdomain/zero/1.0/) applies to the data made available in this article, unless otherwise stated in a credit line to the data. 
The 51-item National Eye Institute Visual Function Questionnaire (NEI-VFQ) was first designed in 1998 [6]. Then a shorter, 25 item, 12 subscales version, known as NEIVFQ-25, was designed and standardized to give respondents more comfortable and improve data quality as well as to measure the health-related quality of life (HRQOL) [7]. The questionnaire has been translated and standardized in Italian, French, Spanish, German, Japanese [8], and also Persian [9].

The VRQoL in ocular disorders such as cataract [10], ocular graft-versus-host disease [11], conjunctivochalasis [12], optic neuropathy [13], and dry eye syndrome [14] have already been studied. Some eye surgeries such as vitrectomy can significantly improve the quality of life of patients with various vitreoretinal disorders [15]. A study of a Japanese population confirmed the negative association between VRQoL and the intensity of ocular diseases [12].

To the best of our knowledge, no population-based study has examined the VRQoL in Iran. Only a clinicalbased study in 2012 on a clinical sample showed that the quality of life in patients with chronic ocular diseases was significantly reduced and was lower in comparison to patients in other countries [16].

This report aims to evaluate vision function and disability as well as related factors using the short-form visual functioning scale (SFVFS), which its validity and reliability have already been verified [9] in a population aged $45-69$ years.

\section{Methods}

\section{Participant and sampling}

This study was conducted using data obtained from 4737 adults (aged 45-69years) at the second phase of the Shahroud eye cohort study in 2014, aiming to identify the causes of eye diseases and visual impairment. The methodology and protocol of study have already been reported [17], but here is a summary.

In the first phase, in 2009, 5190 people aged 40-64 years were selected using random cluster sampling. In the second phase, in 2014, all participants were asked to participate in periodic examinations, where the recall welcomed by 4737 of them (the response rate: $91.3 \%$ ). All participants underwent clinical and para-clinical examinations after conducting interviews.

\section{Short-form visual functioning scale (SFVFS)}

SFVFS is derived from the NEI-VFQ-25 by Pesudovs et al. [18] They showed that NEI-VFQ is not unidimensional questionnaire and some items belong to socioeconomic construct. They segregated the visual functioning items into a scale and made a very effective measure of visual functioning [18]. The interviewer format SFVFS contains six questions; question 1 evaluates the vision of both eyes, and the results ranging from 1 (very good) to 6 (completely blind). Remaining questions which are rated with a 6-point Likert scale evaluate the level of the participant's problems when performing vision-related activities (including text reading, job or leisure, finding things in box, reading driving sign and walking in low light), and the results ranging from 1 (no problem) to 6 (unable for other reasons).

In this study, disability was defined as limitation of activities related to visual problems.

\section{Statistical analysis}

We used the Rasch model, which is a Random Coefficient Multinomial Logit Model, presented for the first time by Conrad et al. [19] for visual studies. Large-scale testing and construct validation research are main advantages of Rasch model. This is an Iterative approach that starts with the general fitting the data into the model and examining the threshold graph, which is used to determine the uneven thresholds. The main parameters in this analysis are thresholds rating and arrangement, fitness statistics and separation indices [20]. The Rasch Rating Scale (RRS) model is generally used for data with categorized rated responses. In this study, we used the modified Rasch scores. The scores range from $-\infty$ to $+\infty$, with the zero as the median score. Regarding the response variable values (1: no problem and 6: impossible/unfeasible), the more negative Rasch scores, the better the visual function and the lesser the visual disability.

Economic status was defined by the Principal Component Analysis on home assets [21]. Quantitative and qualitative data were described using mean \pm standard deviation (SD) with $95 \%$ confidence interval $(95 \% \mathrm{CI})$ and frequency (\%), respectively. Multiple linear regression models were used to estimate the association between SFVFS (outcome index) and gender, education, marital status, insurance coverage and economic status (predictor variables).

\section{Ethical considerations}

This study was conducted in accordance with the Helsinki Declaration. All procedures involving participants and related documentation, as well as the informed consent processes and form were approved by the Ethics Committee of Shahroud University of Medical Sciences (Reference number: 8737). We obtained written informed consent from all participants after explaining the methods and purpose of the research, allowing sufficient time for questions, and ensuring clarity. For subjects who were not able to read the consent materials, the approved oral process was to have the potential participants' representative present the information verbally 
and serve as witness. If oral consent was granted, the fingerprint of the subject was captured, and the witness signed and dated the consent form. The member of the research team in charge of the consent process added a statement that the subject was unable to read the information and that an oral consent process was used.

\section{Results}

Out of 4737 participants in this study, the visual function information of 4715 people aged $55.9 \pm 6.2$ years was available of which 1935 (58.5\%) were male; 4221 (52.59\%) of participants were married, 406 (8.61\%) were widow and the rest were single and divorced;

The visual function of 75.3, 17.1 and $7.5 \%$ of participants were "very good or good", "moderate", and "bad or very bad", respectively, while $0.06 \%$ were unable for vision. The running mean of visual function was calculated to be $-3.95 \pm 0.02$ in total sample.

The visual function status is presented in Table 1, in both visual activity-based and age group-based. When reading a text, the greatest visual problem was observed in the age group of 65-69years old (9.5\%) and

Table 1 Visual functions and disability by age groups in adult population, Shahroud, Iran, 2014

\begin{tabular}{|c|c|c|c|c|c|c|}
\hline \multirow[t]{2}{*}{ Visual functions } & \multicolumn{5}{|c|}{ Age group } & \multirow[t]{2}{*}{ Total } \\
\hline & $45-49$ & $50-54$ & $55-59$ & $60-64$ & $65-69$ & \\
\hline \multicolumn{7}{|l|}{ Text Reading N (\%) } \\
\hline No Problem & $514(58.9)$ & $757(59.5)$ & $713(60.4)$ & $480(55.8)$ & $272(51.0)$ & $2736(58.0)$ \\
\hline Little Problem & $173(19.8)$ & $257(20.2)$ & $208(17.6)$ & $145(16.8)$ & $93(17.4)$ & $876(18.6)$ \\
\hline Moderate Problem & $70(8.0)$ & $79(6.2)$ & $73(6.1)$ & $42(4.8)$ & $27(5.0)$ & $291(6.2)$ \\
\hline High Problem & $81(9.2)$ & $106(8.3)$ & $101(8.5)$ & $77(8.9)$ & $51(9.5)$ & $416(8.8)$ \\
\hline Unable for Vision & $7(0.8)$ & $10(0.7)$ & $7(0.5)$ & $5(0.5)$ & $7(1.3)$ & $36(0.8)$ \\
\hline Unable for other reasons & $27(3.1)$ & $62(4.8)$ & $78(6.6)$ & $110(12.8)$ & $83(15.5)$ & $360(7.6)$ \\
\hline \multicolumn{7}{|l|}{ Job or Leisure N (\%) } \\
\hline No Problem & $447(51.2)$ & $665(52.3)$ & $634(53.7)$ & $438(50.9)$ & $270(50.6)$ & $2454(52.0)$ \\
\hline Little Problem & $205(23.5)$ & $305(24.0)$ & $268(22.7)$ & $199(23.1)$ & $120(22.5)$ & $1097(23.3)$ \\
\hline Moderate Problem & $41(4.7)$ & $86(6.7)$ & $71(6.0)$ & $53(6.1)$ & $34(6.3)$ & $285(6.0)$ \\
\hline High Problem & $156(17.8)$ & $184(14.4)$ & $168(14.2)$ & $138(16.0)$ & $83(15.5)$ & $729(15.5)$ \\
\hline Unable for Vision & $22(2.5)$ & $29(2.2)$ & $38(3.2)$ & $30(3.4)$ & $26(4.8)$ & $145(3.1)$ \\
\hline Unable for other reasons & $1(0.1)$ & $2(0.1)$ & $1(0.08)$ & $1(0.1)$ & $0(0.0)$ & $5(0.1)$ \\
\hline \multicolumn{7}{|l|}{ Finding Things in Box N (\%) } \\
\hline No Problem & $809(92.7)$ & $1138(89.5)$ & $1059(89.7)$ & $769(89.5)$ & $459(86.1)$ & $4234(89.8)$ \\
\hline Little Problem & $41(4.7)$ & $89(7.0)$ & $79(6.6)$ & $52(6.0)$ & $40(7.5)$ & $301(6.4)$ \\
\hline Moderate Problem & $8(0.9)$ & $17(1.3)$ & $17(1.4)$ & $18(2.1)$ & $13(2.4)$ & $73(1.5)$ \\
\hline High Problem & $10(1.1)$ & $20(1.5)$ & $16(1.3)$ & $11(1.2)$ & $15(2.8)$ & $72(1.5)$ \\
\hline Unable for Vision & $3(0.3)$ & $7(0.5)$ & $9(0.7)$ & $9(1.0)$ & $6(1.1)$ & $34(0.7)$ \\
\hline Unable for other reasons & $1(0.1)$ & $0(0.0)$ & $0(0.0)$ & $0(0.0)$ & $0(0.0)$ & $1(0.1)$ \\
\hline \multicolumn{7}{|l|}{ Reading Driving Sign N (\%) } \\
\hline No Problem & $724(83.0)$ & $1034(81.3)$ & $974(82.5)$ & $680(79.1)$ & $409(76.7)$ & $3821(81.0)$ \\
\hline Little Problem & $86(9.8)$ & $130(10.2)$ & $117(9.9)$ & $94(10.9)$ & $63(11.8)$ & $490(10.4)$ \\
\hline Moderate Problem & $40(4.5)$ & $68(5.3)$ & $48(4.0)$ & $48(5.5)$ & $26(4.8)$ & $230(4.9)$ \\
\hline High Problem & $18(2.0)$ & $33(2.6)$ & $31(2.6)$ & $24(2.7)$ & $26(4.8)$ & $132(2.8)$ \\
\hline Unable for Vision & $2(0.2)$ & $2(0.1)$ & $3(0.2)$ & $5(0.5)$ & $4(0.7)$ & $16(3.4)$ \\
\hline Unable for other reasons & $2(0.2)$ & $4(0.3)$ & $7(0.5)$ & $8(0.9)$ & $5(0.9)$ & $26(5.5)$ \\
\hline \multicolumn{7}{|l|}{ Walking in Low Light N (\%) } \\
\hline No Problem & $738(84.6)$ & $1088(85.6)$ & $982(83.2)$ & $701(81.6)$ & $421(78.9)$ & $3930(83.3)$ \\
\hline Little Problem & $81(9.2)$ & $116(9.1)$ & $115(9.7)$ & $78(9.0)$ & $58(10.8)$ & $448(9.5)$ \\
\hline Moderate Problem & $26(2.9)$ & $36(2.8)$ & $39(3.3)$ & $42(4.8)$ & $31(5.8)$ & $174(3.7)$ \\
\hline High Problem & $23(2.6)$ & $23(1.8)$ & $39(3.3)$ & $32(3.7)$ & $18(3.3)$ & $135(2.9)$ \\
\hline Unable for Vision & $3(0.3)$ & $6(0.4)$ & $4(0.3)$ & $6(0.7)$ & $5(0.9)$ & $24(5.1)$ \\
\hline Unable for other reasons & $1(0.1)$ & $2(0.1)$ & $1(0.08)$ & $0(0.0)$ & $0(0.0)$ & $4(0.5)$ \\
\hline
\end{tabular}


45-49 years old (9.2\%), respectively. When finding things in a box, the greatest visual problem was observed at the age ranged $65-69$ years old $(2.8 \%)$ and $50-54$ years old (1.5\%), respectively. In the case of job or leisure, the greatest visual problem was observed in the group aged $45-49$ years $(18 \%)$.

The visual function of the participants is presented in Table 2, in total, and in gender-based. In general, $58 \%$ of the participants did not have any problems when reading the text, while $8.8 \%$ of them experienced serious problems at the same conditions; $52 \%$ of people did not have any visual problems with performing a job or in their leisure, and 10\% experienced inability (at various levels) in finding things in a box. When reading driving signs, $0.8 \%$ of participants did not saw any signs, and $2.8 \%$ had a severe problem in this regard; $83.3 \%$ of the participants were able to walk in low light.

The Rasch results are presented in Table 3. The results of the Multiple Linear Regression model showed that gender, education level, and economic status were factors affecting the visual function score. The running mean was lower in males $(-4.16)$ than females $(-3.81)$ $(\beta=0.14,95 \% C I: 0.04-0.23 ; p=0.005)$. The negative association between education and visual function indicated that visual function score decreases when the education level increases, leading the vision function to improve. For example, the visual function of people with academic education was more desirable than illiterate people $(\beta=-1.06,95 \% \mathrm{CI}:-1.30 ;-0.82 ; p<0.001)$. Also, visual function in participants with moderate $(\beta=0.16$, $\mathrm{p}=0.005)$ and low $(\beta=0.28, \mathrm{p}<0.001)$ economic status was worse than those with high economic status. The relationship between age groups $(P>0.05)$, marital status $(P=0.370)$ and insurance coverage $(P=0.070)$ with visual function were not significant.

\section{Discussion}

Based on the results, in adult population aged $45-69$ years, the visual function of $75,17.1$ and $7.5 \%$ of participants were "very good and good", "moderate", and "bad and very bad", respectively. About a quarter of the participants had visual function less than average. Most of the visual impairments were related to job or leisure, so that nearly half of participants had a weakness in this regard. The least visual disability when finding things in the box was in the near-vision subscale, and about $90 \%$ had no problem with their visual function. Similarly in Gall's study, 177 patients (aged 21-83 years; with a history of stroke and visual field defect) had a mean score 65.25 for the near visual function, which was lower (worse) than the mean scores (72.75) for distance visual function [22]. The greatest

Table 2 Visual functions and disability by gender in adult population, Shahroud, Iran, 2014

\begin{tabular}{|c|c|c|c|c|c|c|}
\hline $\begin{array}{l}\text { Visual } \\
\text { functions }\end{array}$ & No Problem & Little Problem & Moderate Problem & High Problem & Unable for Vision & $\begin{array}{l}\text { Unable } \\
\text { for other } \\
\text { reasons }\end{array}$ \\
\hline \multicolumn{7}{|c|}{ Text Reading N (\%) } \\
\hline All & $2736(58.0)$ & $876(18.5)$ & $291(6.1)$ & $416(8.8)$ & $36(0.7)$ & $360(7.6)$ \\
\hline Male & $1237(63.9)$ & $327(16.9)$ & $113(5.8)$ & $158(8.1)$ & $8(0.4)$ & $92(4.7)$ \\
\hline Female & $149(53.9)$ & $549(19.7)$ & $178(6.4)$ & $258(9.2)$ & $28(1.0)$ & $268(9.6)$ \\
\hline \multicolumn{7}{|c|}{ Job or Leisure N (\%) } \\
\hline All & $2454(52.0)$ & $1,097(23.2)$ & $285(6.0)$ & $729(15.4)$ & $145(3.0)$ & $5(0.1)$ \\
\hline Male & $1340(48.2)$ & $712(25.6)$ & $196(7.0)$ & $448(16.1)$ & $81(2.9)$ & $3(0.1)$ \\
\hline Female & $1114(57.5)$ & $385(19.9)$ & $89(4.6)$ & $281(14.5)$ & $64(3.3)$ & $2(0.1)$ \\
\hline \multicolumn{7}{|c|}{ Finding Things in Box N (\%) } \\
\hline All & $4234(89.8)$ & $301(6.3)$ & $73(1.5)$ & $72(1.5)$ & $34(0.7)$ & $1(0.02)$ \\
\hline Male & $2461(88.5)$ & $203(7.3)$ & $44(1.5)$ & $47(1.6)$ & $25(0.9)$ & $0(0.0)$ \\
\hline Female & $1773(91.6)$ & $98(5.0)$ & $29(1.5)$ & $25(1.2)$ & $9(0.4)$ & $1(0.05)$ \\
\hline \multicolumn{7}{|c|}{ Reading Driving Sign N (\%) } \\
\hline All & $3821(81.0)$ & $490(10.3)$ & $230(4.8)$ & $132(2.8)$ & $16(0.3)$ & $26(0.5)$ \\
\hline Male & $2156(77.5)$ & $331(11.9)$ & $163(5.8)$ & $96(3.4)$ & $11(0.4)$ & $23(0.8)$ \\
\hline Female & $1665(86.0)$ & $159(8.2)$ & $67(3.4)$ & $36(1.8)$ & $5(0.2)$ & $3(0.1)$ \\
\hline \multicolumn{7}{|c|}{ Walking in Low Light N (\%) } \\
\hline All & $3930(83.3)$ & $448(9.5)$ & $174(3.6)$ & $135(2.8)$ & $24(0.5)$ & $4(0.08)$ \\
\hline Male & $2229(80.1)$ & $300(10.7)$ & $124(4.4)$ & $106(3.8)$ & $18(0.6)$ & $3(0.1)$ \\
\hline Female & $1701(87.9)$ & $148(7.6)$ & $50(2.5)$ & $29(1.5)$ & $6(0.3)$ & $1(0.0)$ \\
\hline
\end{tabular}


Table 3 Mean estimation and Multiple linear regression of visual functions by independent variables in Shahroud, Iran, 2014

\begin{tabular}{|c|c|c|c|c|c|c|}
\hline Rmean & & Mean & $95 \% \mathrm{Cl}$ & Coefficient & $95 \% \mathrm{Cl}$ & $p$-value \\
\hline \multirow[t]{5}{*}{ Age group } & $45-49$ & -3.98 & $-4.08,-3.86$ & Ref & & \\
\hline & $50-54$ & -4.02 & $-4.11,-3.93$ & -0.08 & $-0.21,0.05$ & 0.26 \\
\hline & $55-59$ & -4.00 & $-4.09,-3.90$ & -0.10 & $-0.24,0.03$ & 0.15 \\
\hline & $60-64$ & -3.89 & $-4.01,-3.77$ & -0.10 & $-0.25,0.05$ & 0.19 \\
\hline & $65-69$ & -3.74 & $-3.90,-3.59$ & -0.08 & $-0.26,0.09$ & 0.35 \\
\hline \multirow[t]{2}{*}{ Gender } & Male & -4.16 & $-4.23,-4.08$ & $\operatorname{Ref}($ male $=0$, female $=1)$ & & 0.005 \\
\hline & Female & -3.81 & $-3.88,-3.74$ & 0.14 & $0.04,0.23$ & \\
\hline \multirow[t]{3}{*}{ Economic Status } & High & -4.26 & $-4.34,-4.17$ & Ref & & \\
\hline & Moderate & -3.94 & $-4.02,-3.86$ & 0.16 & $0.04,0.27$ & 0.005 \\
\hline & Low & -3.64 & $-3.75,-3.54$ & 0.28 & $0.14,0.42$ & $<0.001$ \\
\hline \multirow[t]{5}{*}{ Education } & Illiterate & -3.15 & $-3.33,-2.97$ & Ref & & \\
\hline & Primary & -3.80 & $-3.90,-3.71$ & -0.59 & $-0.80,-0.39$ & $<0.001$ \\
\hline & Guidance & -3.96 & $-4.08,-3.84$ & -0.69 & $-0.90,-0.48$ & $<0.001$ \\
\hline & High School & -4.20 & $-4.28,-4.11$ & -0.88 & $-1.09,-0.67$ & $<0.001$ \\
\hline & College & -4.47 & $-4.59,-4.35$ & -1.06 & $-1.30,-0.82$ & $<0.001$ \\
\hline
\end{tabular}

visual problem in the age groups of $45-49$ years and 65-69years was observed when reading a text, while in the age group of 65-69years; it was found when finding things in a box. Similar to us, a cross-sectional study on patients with diabetic retinopathy (aged $50-70$ years) by Shrestha et al. [23] showed the greatest disability with near vision activity including legibility of sentences and letters and the least visual disability with clothing. The age was the similar role in current study and a study conducted by Shrestha et al. [23], where the majority of participants were in the age group of over 50 years old and reading or writing a text was the most common visual disability observed.

In contrast to present results, a population-based study [24] examined the visual function in 12,231 German participants with mean age $66.95 \pm 14.7$ years and showed a significant correlation between the lower scores and higher ages $(-0.48, P<0.001)$. The different age groups and age range of participants, sample size, life style (in the term of hours spending for reading, hubbies, work and ...), education level, culture (living alone or with family) and accessibility to medical and supportive services can justify the differences in the results of the two studies.

The present study showed that the visual function in females was worse than that of males. Gall et al. reported that the visual function score of females was 1.57 less than males [22], under constant age, socioeconomic status and visual acuity [24]. As shown in previous studies [25, 26], females receive less eye care services for vision correction. Also, the complications of cataract surgery in females are greater than males while they receive less postoperative cares and services
[27]. Also, gender differences can be related to fewer problems in social functioning in females [28].

There was a positive correlation between visual function with increasing education level and improving the economic status in the current study. Similarly Ulldemolins et al. [29] showed a negative correlation between the improved socioeconomic status (e.g., higher education, high income, non-manual occupational social class, etc.) with the prevalence of blindness or visual impairment in a review study.

World Health Organization recommend a framework known as International Classification of Functioning, Disability and Health (ICF) for classification of health and health-related domains since 2001 [30]. To the best of our knowledge there is no report, comparing SFVFS with ICF or even the new WHODAS 2.0 for measuring health and disability. The comparison of these tools needs new and comprehensive studies.

Standard design, large sample size, population-based design and response rate of over $90 \%$ are among the strengths of this study. The impossibility of generalizing the results to the entire population of Iran may be considered as a limitation of this study. It should be also noted that visual function associated factors, investigated in regression model, do not necessarily have a causal effect in this cross-sectional study.

\section{Conclusion}

Only $7.5 \%$ of adults aged $45-69$ years old had bad or very bad visual function. However, it was more impaired in females, low educated and low economic groups which should be considered for policymaking. 


\section{Abbreviations}

SFVFS: Short-Form Visual Functioning Scale; NEI-VFQ: National Eye Institute Visual Functioning Questionnaire; VRQoL: Vision-related quality of life; Cl: Confidence Intervals; SD: Standard Deviation.

\section{Acknowledgements}

Not applicable.

\section{Authors' contributions}

$\mathrm{HH}, \mathrm{FM}$ and SA drafted the manuscript and contributed in preparation of the study protocol and conceptualized and conducted all statistical analyses and were the primary authors of the article. MHE, $\mathrm{HH}$ and $\mathrm{AF}$ contributed in the conceptualization of the paper and the statistical analyses and critically revised the manuscript. All authors read and approved the final manuscript.

\section{Funding}

Shahroud Eye Cohort Study is supported by Noor Eye Hospital and Shahroud University of Medical Sciences (project number: 9826).

\section{Availability of data and materials}

The datasets used and/or analyzed during the current study are available from the corresponding author on reasonable request.

\section{Declarations}

\section{Ethics approval and consent to participate}

This study was conducted in accordance with the Helsinki Declaration. All procedures involving participants and related documentation, as well as the informed consent processes and form were approved by the Ethics Committee of Shahroud University of Medical Sciences (Reference number: 8737). We obtained written informed consent from all participants after explaining the methods and purpose of the research, allowing sufficient time for questions, and ensuring clarity. For subjects who were not able to read the consent materials, the approved oral process was to have the potential participants representative present the information verbally and serve as witness. If oral consent was granted, the fingerprint of the subject was captured, and the witness signed and dated the consent form. The member of the research team in charge of the consent process added a statement that the subject was unable to read the information and that an oral consent process was used.

\section{Consent for publication}

Not applicable.

\section{Competing interests}

The authors declare that they have no competing interests.

\section{Author details}

${ }^{1}$ Noor Ophthalmology Research Center, Noor Eye Hospital, Tehran, Iran. ${ }^{2}$ Department of Epidemiology and Biostatistics, School of Public Health, Tehran University of Medical Sciences, Tehran, Iran. ${ }^{3}$ Ophthalmic Epidemiology Research Center, Shahroud University of Medical Sciences, Shahroud, Iran.

Received: 26 March 2021 Accepted: 19 January 2022

Published online: 20 January 2022

\section{References}

1. World Health Organization. Blindness and vision impairment. 2021. https://www.who.int/en/news-room/fact-sheets/detail/blindness-andvisual-impairment. Accessed 11 Nov 2021.

2. Keel S, Cieza A. Rising to the challenge: estimates of the magnitude and causes of vision impairment and blindness. Lancet Glob Health. 2021;9:e100-1. https://doi.org/10.1016/S2214-109X(21)00008-5.

3. Virchow J, Kay S, Demoly P, Mullol J, Canonica W, Higgins V. Impact of ocular symptoms on quality of life (QoL), work productivity and resource utilisation in allergic rhinitis patients-an observational, cross-sectional study in four countries in Europe. J Med Econ. 2011;14:305-14. https:// doi.org/10.3111/13696998.2011.576039.
4. Hazel CA, Petre KL, Armstrong RA, Benson MT, Frost NA. Visual function and subjective quality of life compared in subjects with acquired macular disease. Invest Ophthalmol Vis Sci. 2000:41:1309-15.

5. Angeles-Han ST, Griffin KW, Harrison MJ, et al. Development of a vision-related quality of life instrument for children ages 8-18 years for use in juvenile idiopathic arthritis-associated uveitis. Arthritis Car Res. 2011:63:1254-61. https://doi.org/10.1002/acr.20524.

6. Mangione CM, Berry S, Spritzer K, et al. Identifying the content area for the 51-item National eye Institute visual function questionnaire: results from focus groups with visually impaired persons. Arch Ophthalmol. 1998;116:227-33. https://doi.org/10.1001/archopht.116.2.227.

7. Mangione CM, Lee PP, Gutierrez PR, Spritzer K, Berry S, Hays RD. Development of the 25-list-item national eye institute visual function questionnaire. Arch Ophthalmol. 2001;119:1050-8. https://doi.org/10.1001/archo pht.119.7.1050

8. Suzukamo Y, Oshika T, Yuzawa M, et al. Psychometric properties of the 25-item national eye institute visual function questionnaire (NEI VFQ-25). Japanese version Health Qual Life outcomes. 2005;3:65. https://doi.org/ 10.1186/1477-7525-3-65.

9. Asgari S, Hashemi H, Nedjat S, Shahnazi A, Fotouhi A. Persian version of the 25-item National eye Institute visual functioning questionnaire (NEIVFQ 39): a validation study. Iran J Ophthalmol. 2011;23:5-14.

10. Polack S, Kuper H, Mathenge W, Fletcher A, Foster A. Cataract visual impairment and quality of life in a Kenyan population. Br J Ophthalmol. 2007:91:927-32. https://doi.org/10.1136/bjo.2006.110973.

11. Saboo US, Amparo F, Abud TB, Schaumberg DA, Dana RJO. Vision-related quality of life in patients with ocular graft-versus-host disease. Ophthalmology. 2015;122:1669-74. https://doi.org/10.1016/j.ophtha.2015.04.011.

12. Gander J, Sui X, Hazlett LJ, Cai B, Hebert JR, Blair SN. Factors related to coronary heart disease risk among men: validation of the Framingham risk score. Prev Chronic Dis. 2014;11:E140. https://doi.org/10.5888/pcd11. 140045.

13. Broesel D, Sabel B, Franke G, Gall C. P635: quality of life and visual impairment in patients with optic neuropathy before and after non-invasive electrical stimulation. Clin Neurophysiol. 2014;125. https://doi.org/10. 1016/S1388-2457\%2814\%2950730-4.

14. Miljanović B, Dana R, Sullivan DA, Schaumberg DA. Impact of dry eye syndrome on vision-related quality of life. Am J Ophthalmol. 2007;143:409_ 15. https://doi.org/10.1016/j.ajo.2006.11.060.

15. Okamoto F, Okamoto Y, Fukuda S, Hiraoka T, Oshika T. Vision-related quality of life and visual function after vitrectomy for various vitreoretinal disorders. Invest Ophthalmol Vis Sci. 2010;51:744-51. https://doi.org/10. 1167/iovs.09-3992.

16. Asgari S, Nedjat S, Hashemi H, Shahnazi A, Fotouhi A. Quality of life in the group of patients with chronic eye disease. Iran J Epidemiol. 2012;7:43-8.

17. Fotouhi A, Hashemi H, Shariati M, et al. Cohort profile: Shahroud eye cohort study. Int J Epidemiol. 2013;42:1300-8. https://doi.org/10.1093/ije/ dys 161.

18. Pesudovs K, Gothwal VK, Wright T, Lamoureux EL. Remediating serious flaws in the National eye Institute visual function questionnaire. J Cataract Refract Surg. 2010;36:718-32. https://doi.org/10.1016/j.jcrs.2009.11. 019.

19. Conrad KJ, Smith EV Jr. International conference on objective measurement: applications of Rasch analysis in health care. Med Care. 2004;42:116. https://doi.org/10.1097/01.mlr.0000103527.52821.1c.

20. Gothwal VK, Wright TA, Lamoureux EL, Pesudovs K. Rasch analysis of the quality of life and vision function questionnaire. Optom Vis Sci. 2009;86:E836-E44. https://doi.org/10.1097/OPX.0b013e3181bab10c.

21. Raznahan M, Emamian MH, Hashemi H, Zeraati H, Fotouhi A. Assessment of horizontal inequity in eye care utilization in the Iranian middleaged population. J Ophthalmic Vis Res 2018;13:284-92. 10.4103/jovr. jovr_221_17.

22. Gall C, Franke GH, Sabel BA. Vision-related quality of life in first stroke patients with homonymous visual field defects. Health Qual Life Outcomes 2010;8:33. 10.1186/1477-7525-8-33.

23. Shrestha GS, Kaiti R. Visual functions and disability in diabetic retinopathy patients. J Optom. 2014;10.1016/j.optom.2013.03.003(7):37-43.

24. Nickels S, Schuster AK, Singer S, et al. The National eye Institute 25-item visual function questionnaire (NEI VFQ-25)-reference data from the German population-based Gutenberg health study (GHS). Health Qual Life Outcomes 2017:15:156. 10.1186/s12955-017-0732-7. 
25. Khandekar R, Mohammed AJljoo. Gender inequality in vision loss and eye diseases: evidence from the Sultanate of Oman. Indian J Ophthalmol 2009:57:443. 10.4103/0301-4738.57153.

26. Ramke J, Gilbert CE, Lee AC, Ackland P, Limburg H, Foster A. Effective cataract surgical coverage: an indicator for measuring quality-of-care in the context of universal health coverage. PLoS One 2017;12:e0172342. 10.1371/journal.pone.0172342.

27. Hashemi H, Rezvan F, Fotouhi A, et al. Distribution of cataract surgical rate and its economic inequality in Iran. Optom Vis Sci. 2015;10.1097/ OPX.00000000000000590(92):707-13.

28. Havstam Johansson L, Škiljić D, Falk Erhag H, et al. Vision-related quality of life and visual function in a 70-year-old Swedish population. Acta Ophthalmol. 2020. https://doi.org/10.1111/aos.14341.

29. Ulldemolins AR, Lansingh VC, Valencia LG, Carter MJ, Eckert KA. Social inequalities in blindness and visual impairment: a review of social determinants. Indian J Ophthalmol. 2012;60:368. https://doi.org/10.4103/ 0301-4738.100529.

30. World Health Organization. International Classification of Functioning, Disability and Health (ICF). https://www.who.int/standards/classifica tions/international-classification-of-functioning-disability-and-healt h\#: : text=The\%20International\%20Classification\%20of\%20Function ing,health\%20and\%20health-related\%20domains.\&text=|CF\%20is\%20 the\%20WHO\%20framework,both\%20individual\%20and\%20population\%20levels. Accessed: June 12, 2021.

\section{Publisher's Note}

Springer Nature remains neutral with regard to jurisdictional claims in published maps and institutional affiliations.

- fast, convenient online submission

- thorough peer review by experienced researchers in your field

- rapid publication on acceptance

- support for research data, including large and complex data types

- gold Open Access which fosters wider collaboration and increased citations

- maximum visibility for your research: over $100 \mathrm{M}$ website views per year

At BMC, research is always in progress.

Learn more biomedcentral.com/submissions 